\title{
Increasing rates of anterior cruciate ligament reconstruction in young Australians, 2000-2015
}

\author{
David Zbrojkiewicz',2, Christopher Vertullo,3, Jane E Grayson ${ }^{4}$
}

The known Rupture of the anterior cruciate ligament $(A C L)$ is a common and devastating injury that is largely preventable by neuromuscular agility training.

The new The incidence of $A C L$ reconstructions in Australia is the highest in the world, and is increasing. At greatest risk are men aged 20-24 years and women aged 15-19 years, but incidence is increasing most rapidly among 5-14-year-old children. The incidence of revision $A C L$ is increasing more rapidly than that of primary $A C L$ reconstructions.

The implications These findings justify establishing a national $A C L$ injury prevention program and an $A C L$ reconstruction registry to improve outcomes for active young Australians.

$\mathrm{R}$ upture of the anterior cruciate ligament (ACL) is a common and debilitating injury that typically results from a non-contact event in which a previously healthy individual changes direction at speed while playing a multidirectional sport. ACL ruptures were once thought to be uncommon in the skeletally immature, ${ }^{1}$ but recent evidence suggests that the global burden of ACL injury falls increasingly on adolescents and young adults. ${ }^{2,3}$ The short term consequences of ACL rupture include the inability to participate in sport, reconstructive surgery, and prolonged rehabilitation. ${ }^{4}$ In the long term, regardless of whether or not an ACL reconstruction is performed, almost all individuals who tear an ACL are at increased risk of osteoarthritis and disability, ${ }^{4-6}$ and this risk is substantially increased by concurrent meniscal injury. ${ }^{4}$

Descriptive analyses of population-based data indicate that the incidence of ACL reconstruction in Australia is among the highest in the world. ${ }^{2,7}$ Recent analyses of data in Victorian injury databases have found increasing rates of sport-related hospitalisations and lower limb injuries in older children and young adults, ${ }^{3,8}$ but it is uncertain whether this trend applies to the entire country, is confined to younger people, or is sex-specific.

Several studies have found that neuromuscular agility and proprioceptive training programs are effective as preventive measures, averting $50-80 \%$ of ACL injuries. ${ }^{9-11}$ Sports injuries, particularly ACL injuries, are emerging as an internationally recognised public health problem, making it vital that the demographic features associated with an increased risk of ACL injury are characterised.

The aim of our study was to investigate the incidence and demographic features of ACL reconstructions in Australia, by age and sex, and to determine whether the incidence of ACL reconstructions has changed during the past 15 years.

\section{Methods}

\section{Study design}

Longitudinal data for ACL reconstructions were extracted from the National Hospital Morbidity Database (NHMD) of the Australian

\section{Abstract}

Objectives: To investigate the incidence and demographic features of anterior cruciate ligament $(\mathrm{ACL})$ reconstructions in Australia by age and sex, and to determine whether the incidence has changed during the past 15 years.

Design and setting: Descriptive epidemiological analysis of longitudinal data on ACL reconstructions (July 2000 - June 2015) in the National Hospital Morbidity Database.

Main outcome measures: Population $\mathrm{ACL}$ reconstruction rates, by age group and sex.

Results: 197557 primary ACL reconstructions were performed during the study period; the annual incidence increased by 43\% (from 54.0 to 77.4 per 100000 population), and by $74 \%$ among those under 25 years of age (from 52.6 to 91.4 per 100000 population). In males, the peak incidence in 2014-15 was for 20-24-year-olds (283 per 100000 population); for females, it was for 15-19-year-olds (164 per 100000 population). Annual growth in incidence was greatest in the 5-14-year-old age group (boys, 7.7\%; girls, 8.8\%). Direct hospital costs of $\mathrm{ACL}$ reconstruction surgery in 2014-15 were estimated to be $\$ 142$ million. The annual incidence of revision ACL reconstructions increased from 2.49 (2000-01) to 5.65 per 100000 population (2014-15), or by 5.6\% per year; revisions as a proportion of all $\mathrm{ACL}$ reconstruction increased from $4.4 \%$ to $6.8 \%$.

Conclusions: The increasing incidence of $\mathrm{ACL}$ reconstructions in young Australians over 15 years is worrying. The individuals at greatest risk are men aged 20-24 years and women aged 15-19 years; the rate of reconstruction is increasing most rapidly among those aged 5-14 years. Revision rates are increasing more rapidly than those of primary reconstructions.

Institute of Health and Welfare (AIHW) (http://www.aihw.gov. au/hospitals-data/procedures-data-cubes). The NHMD comprises confidential electronic record summaries for episodes of care provided by state and territory health authorities, including data from public and private hospitals, as well as from private surgical centres. The database affords national coverage of information on inpatient hospital treatments, with a negligible proportion of missing data $\left(0.004 \%\right.$ of cases per year). ${ }^{12}$ The database collects information on the type of procedure (according to the International Statistical Classification of Diseases and Related Health Problems, 10th revision, Australian modification [ICD-10-AM] ${ }^{13}$ and the third to eighth editions of the Australian Classification of Health Interventions $[\mathrm{ACHI}]^{14}$ ), year of procedure, sex and age group of patient, and whether the procedure required day or overnight admission.

Patients who underwent a primary knee reconstruction during the period 1 July 2000 - 30 June 2015 were identified by ICD-10-AM block number 1522 (with ICD-10-AM procedure codes 49539-00, 49539-01, 49542-00, 49542-01). AIHW procedure numbers included both isolated cruciate reconstruction and cruciate reconstruction with concurrent meniscal injury. Revision knee reconstructions 
were identified by ICD-10-AM block number 1524 with the ICD procedure code 49551-00.

ACL incidence rates were expressed as number per 100000 population for each year of the study, based on Australian Bureau of Statistics population figures. ${ }^{15}$

\section{Statistical analysis}

Trends in population-adjusted numbers of procedures were analysed in SPSS Statistics 23 (IBM). $P<0.05$ was deemed statistically significant.

\section{Ethics approval}

The base data for this investigation were de-identified data publicly available from the AIHW. Our investigation was therefore granted exemption from formal ethics review by the Griffith University Human Research Ethics Committee.

\section{Results}

During 2000-2015, 197557 primary ACL reconstructions were performed in Australia: 134695 (68.2\%) in males and 62862 $(31.8 \%)$ in females. The annual number of primary ACL reconstructions increased from 9662 in 2000-01 to 16990 in 2014-15; the overall incidence of ACL reconstructions increased by $43 \%$ during this period, from 54.0 to 77.4 per 100000 population. The rate in males increased from 73.3 to 101.6 per 100 000, in females from 35.0 to 53.4 per 100000 population (average annual growth rates of $2.2 \%$ and $2.9 \%$ respectively) (Box 1 ).

Throughout the study period, the rates were higher for males than for females in all 5-year age groups. In males, the peak incidence in 2014-15 was for the 20-24-year-old group (283 per 100000 population), but rates were also high for 15-19-year-olds (241 per $100000)$ and 25-29-year-olds (232 per 100000$)$. In females, the peak incidence was for the 15-19-year-old group (164 per 100000 population) (Box 2, Box 3).

Annual growth in the incidence of ACL reconstruction was highest for the 5-14-year-old age group (7.7\% for males, $8.8 \%$ for females); the rates for $15-19$-year-olds were $4.4 \%$ (males) and $5.0 \%$ per year (females). The growth rates were also large for older age groups: $5.3 \%$ (males) and $4.2 \%$ annually (females) for people aged 45-49 years, and $6.0 \%$ (males) and $4.8 \%$ per year (females) for those aged 50-54 years (Box 4).

During the 15-year period analysed, the annual incidence of ACL reconstruction in people under 25 years of age grew by a total of $73.8 \%$ (3.8\% per year); the incidence for those aged 25 or more increased by $28.4 \%$ (1.7\% per year) (Box 5$)$. The incidence in females under 25 grew by a total of $90.6 \%$ (4.4\% per year), in males under 25 by $69.3 \%$ (3.7\% per year) (Box 6). Incidence rates for 2015-16 to 2024-25 were forecast by assuming that trends over the past 15 years will be maintained. On this basis, overall growth in incidence for the period 2000-01 to 2024-25 will be greatest for females under 25 (239\%, or $8.5 \%$ per year); the projected total growth for males under 25 is $119 \%$ (5.4\% per year), and for all people over 25 it is $48.7 \%$ (2.7\% per year) (Box 6$)$.

\section{Estimated costs of anterior cruciate ligament surgery}

According to the 2017 variance report of the Royal Australasian College of Surgeons and Medibank, the average direct hospital and surgery cost per ACL reconstruction was $\$ 8364 .{ }^{16}$ The estimated direct costs of primary ACL reconstruction surgery in 2014-15 were $\$ 142$ million. This figure does not include the rehabilitation, disease burden, and societal costs associated with the injury.
1 Incidence of primary anterior cruciate ligament reconstruction in Australia, 2000-2015, by sex

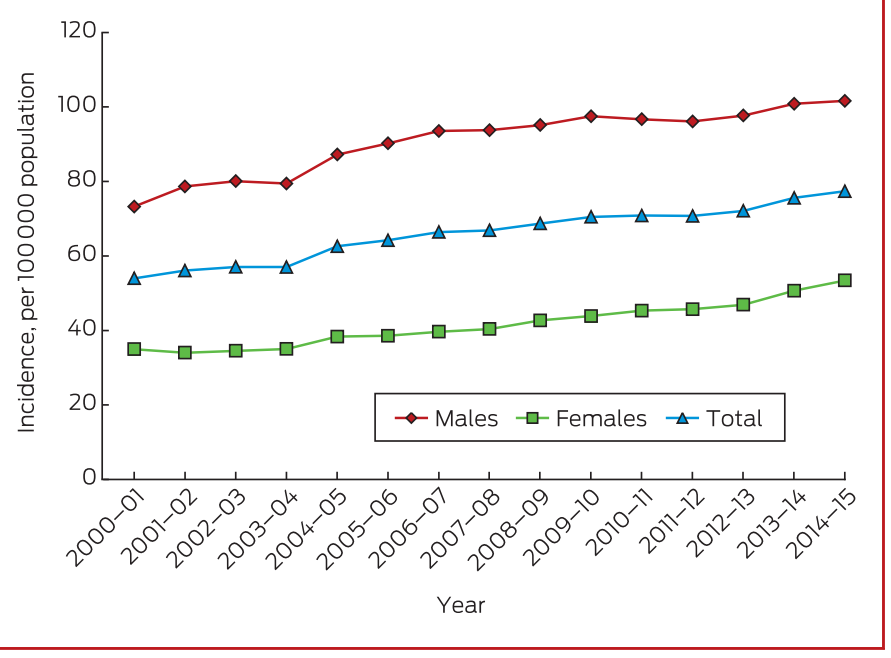

2 Incidence of primary anterior cruciate ligament reconstruction in males, 2000-2015, by age group

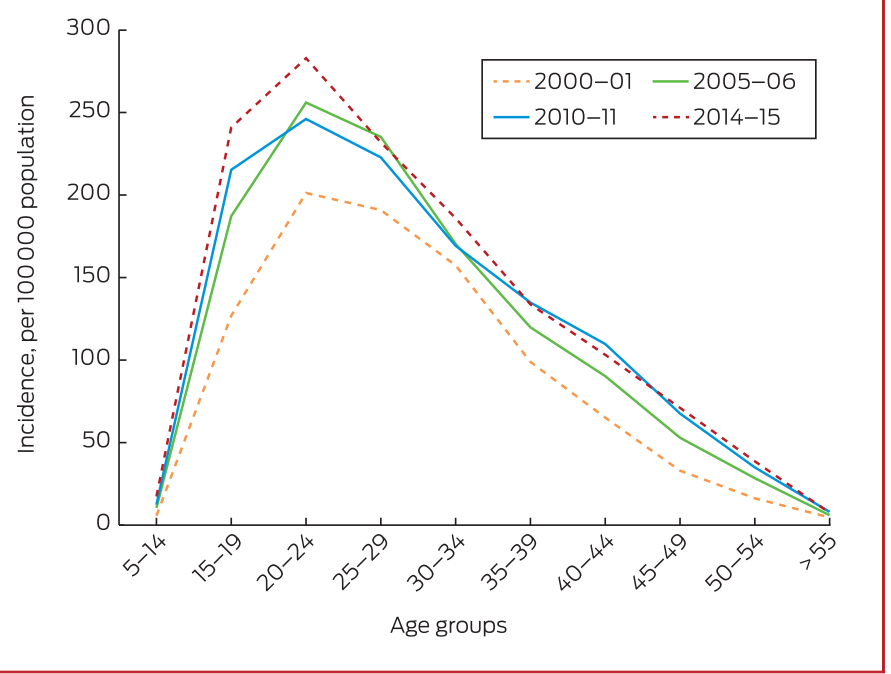

3 Incidence of primary anterior cruciate ligament reconstruction in females, 2000-2015, by age group

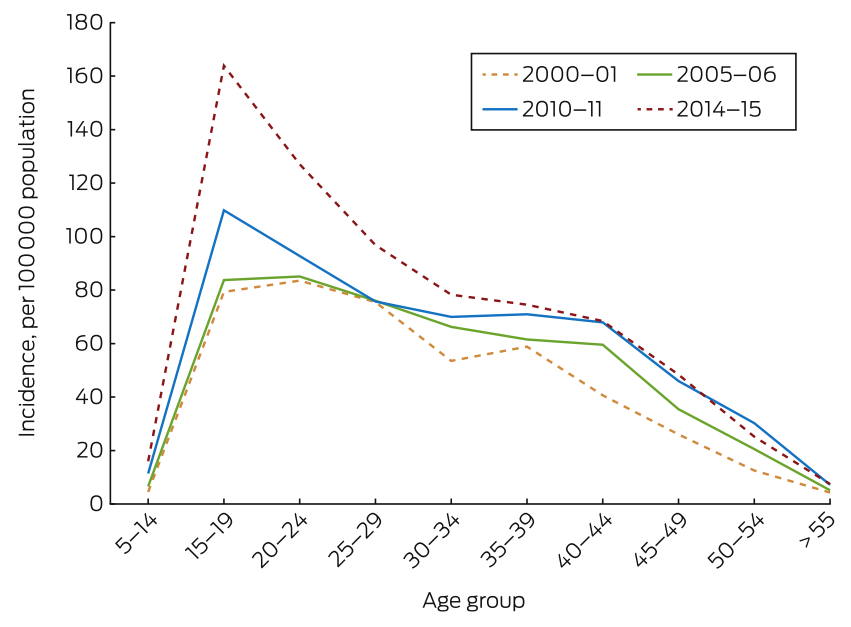




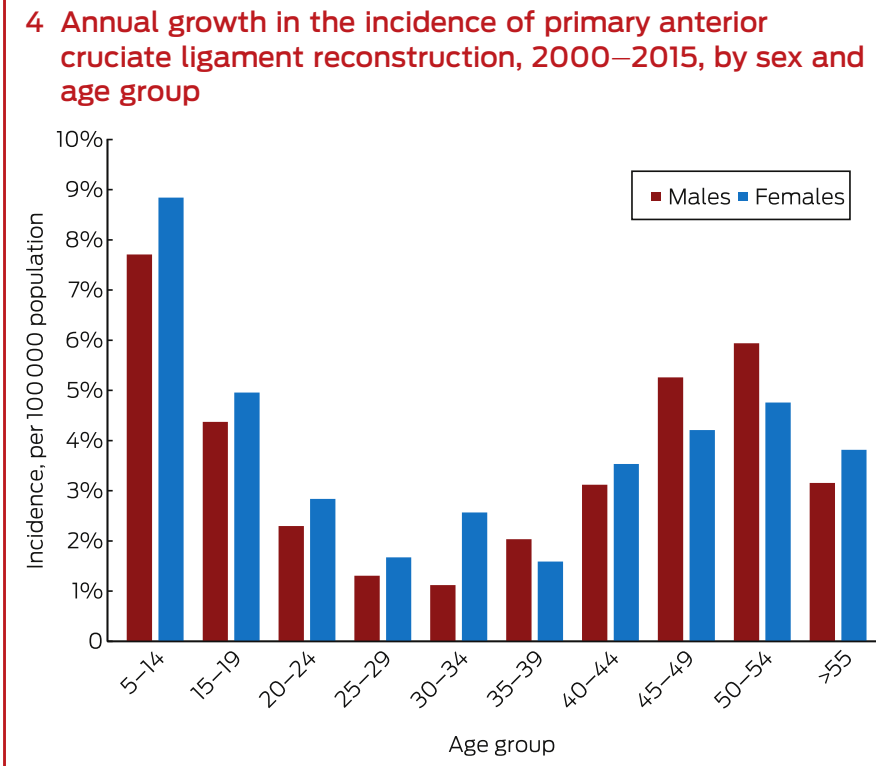

\section{Revision anterior cruciate ligament surgery}

A total of 12878 revision ACL reconstructions were reported during 2000-01 to 2014-15; 9588 (74.5\%) were for males and 3290 $(25.5 \%)$ for females. The annual number increased from 477 in $2000-01$ and to 1328 in $2014-15$; the annual incidence increased by $127 \%$, from 2.49 to 5.65 per 100000 population, or by $5.6 \%$ per year. The incidence in males increased from 3.62 to 8.35 per 100000 population (5.7\% per year), in females from 1.37 to 2.98 per 100000 population (5.3\% per year) (Box 7). Revision ACL reconstructions as a proportion of all reconstructions increased from $4.4 \%$ in $2000-01$ to $6.8 \%$ in $2014-15$.

\section{Discussion}

During 2000-2015, the incidence of ACL reconstruction surgery increased in Australia in all age groups; the overall incidence was greatest among 15-24-year-olds. Consistent with other recent reports, ${ }^{1,3,17}$ the rate of growth in incidence was greatest among 5-14-year-old children.

Our calculated primary ACL reconstruction incidence of 77.4 per 100000 population is the highest populationadjusted rate in the world; lower rates in comparable Organisation for Economic Cooperation and Development (OECD) nations include those for the United States (52), New Zealand (37), Denmark (38), Norway (34), and Sweden (32 per 100000 population).?

We identified age and sex differences in the incidence of ACL reconstruction surgery, with the peak incidence in males being for a slightly older age group and $73 \%$ higher than the peak incidence in females. This is consistent with studies that have reported higher rates of ACL reconstruction in males, ${ }^{2,18,19}$ despite females being two to ten times more likely to rupture their ACL when participating in high risk sports such as basketball and soccer. ${ }^{20,21}$ It is conceivable that the higher incidence in males reflects greater participation in sports such as Australian rules football, in which pivoting, jumping and rapid deceleration increase the risk of ACL injury. ${ }^{22}$

That the peak incidence for females is in a younger age group is consistent with their higher rates of sports

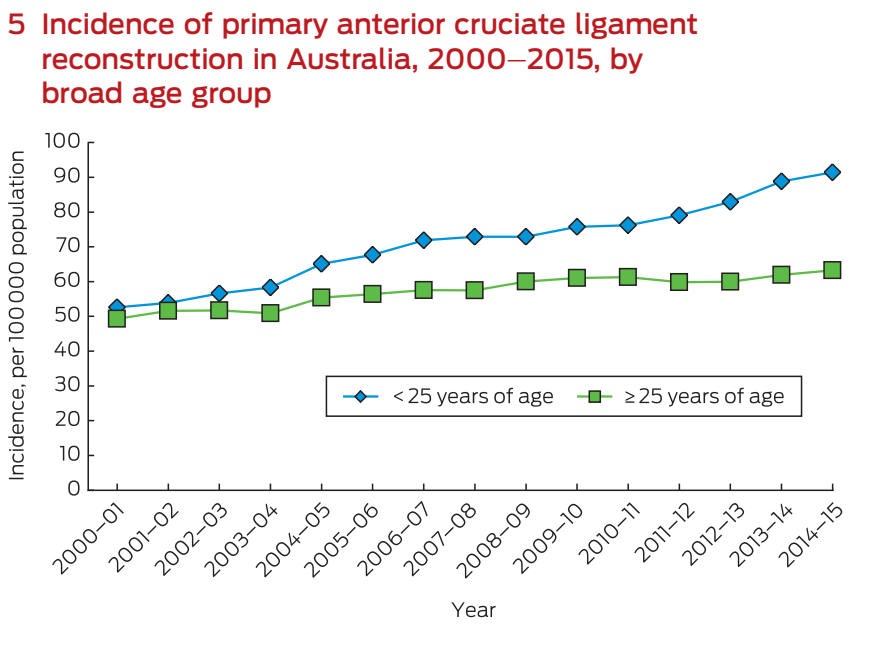

participation during early adolescence, declining when they reach $18-24$ years. $^{23}$

ACL rupture imposes a considerable health burden on a young and active population. We identified an annual incidence growth in its incidence for Australians under 25 of $3.8 \%$, compared with $1.7 \%$ for those over 25. Moreover, growth in reconstruction incidence was most rapid for boys $(7.7 \%)$ and girls $(8.8 \%)$ aged $5-14$ years, although it should be noted that the base ACL reconstruction incidence in this age group was low. The increased incidence in children is nevertheless of particular concern, as ACL injury in this age group was previously rare. The burden of future degenerative disease falls most heavily on our youngest patients. ${ }^{24}$

The rising incidence of ACL reconstruction during 2000-2015 can be attributed to several factors, including increasing medical and public awareness of the procedure, diagnostic improvements, the availability of magnetic resonance imaging, and increased access to orthopaedic surgeons. ${ }^{3,25,26}$ About $72 \%$ of ACL reconstructions in Australia are sport-related; the sports most frequently involved are Australian rules football, rugby union, rugby league, netball, basketball, soccer, and skiing. ${ }^{2,4}$ The rise of ACL injury in young people has been attributed to earlier specialisation by younger
6 Incidence of primary anterior cruciate ligament reconstruction in Australia, 2000-2015, by sex and broad age group

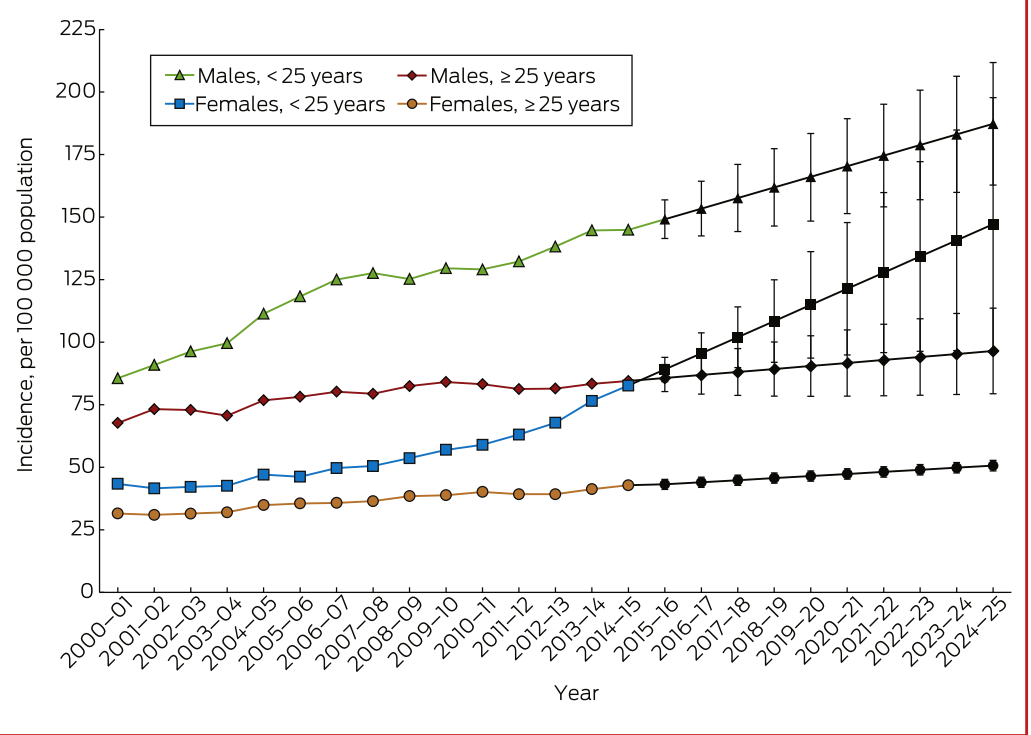


7 Incidence of revision anterior cruciate ligament reconstruction in Australia, 2000-2015, by sex

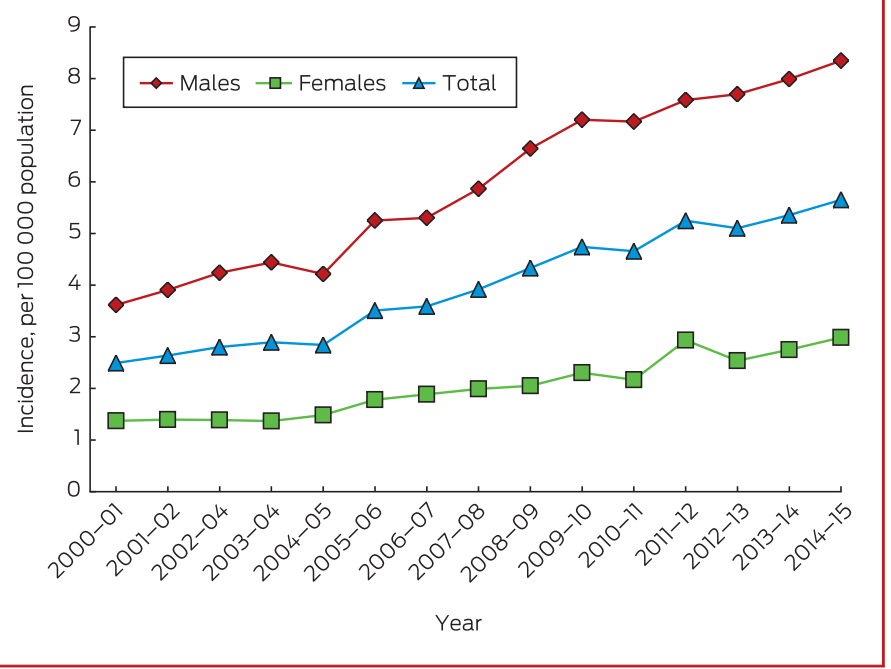

athletes, longer sporting seasons, more intense training, higher levels of competition, ${ }^{1}$ and a lack of free play. ${ }^{25-27}$

The costs of ACL injury can be divided into direct and indirect costs. We estimated the direct hospital costs for ACL reconstructions were $\$ 142$ million in $2014-15$, a substantial cost to the health care system that is growing with the incidence of ACL injuries. Despite the considerable direct hospital costs, ACL reconstruction surgery is significantly more cost-effective than rehabilitation alone in both the short and long term, with patients experiencing greater improvements in quality-adjusted life-years at a lower cost. ${ }^{28}$ An American group calculated the average lifetime costs to society per ACL rupture to be \$US88 938 with rehabilitation only and \$US38 121 with ACL reconstruction. ${ }^{28}$ In young people, delaying ACL reconstruction surgery or opting for nonoperative management is associated with significantly poorer outcomes in both the short and long terms. ${ }^{29}$

Nevertheless, prevention is much more cost-effective than either ACL reconstruction or rehabilitation. Establishing a national ACL injury prevention program has been reported as a cost-effective strategy for improving sporting health outcomes for young Australians, with low barriers to implementation. ${ }^{4}$ In addition to reducing health care costs, prevention programs allow athletes to avoid the consequences of injury, including reduced functional capacity because of pain, chronic knee instability, ${ }^{28}$ and time away from work or education. ${ }^{30}$ In the longer term, the future complications of osteoarthritis ${ }^{4}$ can lead to loss of productivity, fewer employment opportunities, reduced social interaction, and lower quality of life.

The link between ACL injury and knee replacement later in life is also important. ${ }^{5,6}$ The incidence of knee replacements in Australia is high compared with other OECD nations, and it is expected to continue to increase. ${ }^{32}$ An estimated annual loss of $\$ 9.4$ billion in GDP has been attributed to early retirement caused by arthritis in Australia. $^{33}$

The incidence of revision ACL reconstruction surgery increased across the study period by an average $5.6 \%$ per year, and the proportion of reconstructions that were revision reconstructions rose from $4.4 \%$ to $6.8 \%$. While graft position, tunnel placement, younger age, and early return to sport are established risk factors for ACL graft failure, ${ }^{34,35}$ further investigations are warranted, and the need to carefully document emerging trends, risk factors and the effects of interventions would justify the establishment of a national ACL reconstruction registry. ${ }^{36}$

As we analysed national electronic records summaries for episodes of care, our investigation had some limitations. Firstly, AIHW procedural data cubes did not allow differentiation between ACL and posterior cruciate ligament (PCL) reconstructions. While isolated PCL injuries requiring reconstruction are uncommon (fewer than $1 \%$ of all knee injuries seen in the clinic), ${ }^{37}$ the risk of osteoarthritis after PCL reconstruction is similar to that for ACL reconstruction. Secondly, the AIHW data did now allow analysis of reconstruction rates by state and territory, limiting our analysis to the national scale. Additionally, as with any database study, coding errors are possible. Accurate direct hospital costs per ACL reconstruction were unavailable for 2014-15, and the estimated costs for this year were calculated using 2017 costing data. The validity of comparing ACL reconstruction rates in different countries is limited by the availability of data on the incidence of ACL injuries and reconstruction, which are related but distinct phenomena. While the rate of ACL reconstruction may be an indirect measure of that of ACL injury, many ACL injuries are either not diagnosed or do not lead to surgical reconstruction.

\section{Conclusion}

This Australian population-level data analysis found a worrying increase in the incidence of ACL reconstructions in young Australians during 2000-2015. Most such reconstructions could be averted by neuromuscular agility training and other preventive measures. The individuals at greatest risk are men aged 20-24 years and women aged 15-19 years; the rate of reconstruction is increasing most rapidly among boys and girls aged 5-14 years. Moreover, rates of revision reconstruction are increasing more rapidly than the rate of primary ACL reconstructions. The increasing incidence of ACL injury in Australia is an emerging public health problem with potentially detrimental long term health outcomes, especially for young people.

\section{Competing interests: No relevant disclosures}

Received 5 Oct 2017, accepted 12 Dec 2017.

(c) 2018 AMPCo Pty Ltd. Produced with Elsevier B.V. All rights reserved.
1 Dodwell ER, Lamont LE, Green DW, et al. 20 years of pediatric anterior cruciate ligament reconstruction in New York State. Am J Sports Med 2014; 42: 675-680.

2 Janssen K, Orchard JW, Driscoll TR, et al. High incidence and costs for anterior cruciate ligament reconstructions performed in Australia from 2003-2004 to 20072008: time for an anterior cruciate ligament register by Scandinavian model? Scand J Med Sci Sports 2011; 22: 495-501.
3 Shaw L, Finch CF. Trends in pediatric and adolescent anterior cruciate ligament injuries in Victoria, Australia 2005-2015. Int J Environ Res Public Health 2017; 14: E599.

4 Lewis DA, Kirkbride B, Vertullo CJ, et al. Comparison of four alternative national universal anterior cruciate ligament injury prevention programme implementation strategies to reduce secondary future medical costs. $\mathrm{Br} J$ Sports Med 2018; 52: 277-228.
5 von Porat A. High prevalence of osteoarthritis 14 years after an anterior cruciate ligament tear in male soccer players: a study of radiographic and patient relevant outcomes. Ann Rheum Dis 2004; 63 : 269-273.

6 Lohmander LS, Englund PM, Dahl LL, et al. The longterm consequence of anterior cruciate ligament and meniscus injuries osteoarthritis. Am J Sports Med 2007; 35: 1756-1769. 
7 Moses B, Orchard J, Orchard J. Annual incidence of ACL injury and surgery in various populations. Res Sports Med 2012; 20: 157-179.

8 Finch CF, Kemp JL, Clapperton AJ. The incidence and burden of hospital-treated sports-related injury in people aged 15+ years in Victoria, Australia, 2004 -2010: a future epidemic of osteoarthritis? Osteoarthritis Cartilage 2015; 23: 1138-1143.

9 Sadoghi P, von Keudell A, Vavken P. Effectiveness of anterior cruciate ligament injury prevention training programs. J Bone Jt Surg Am 2012; 94: 769-776.

10 Myklebust G, Skjolberg A, Bahr R. ACL injury incidence in female handball 10 years after the Norwegian $A C L$ prevention study: important lessons learned. Br J Sports Med 2013; 47: 476-479.

11 Mandelbaum BR, Silvers HJ, Watanabe DS, et al. Effectiveness of a neuromuscular and proprioceptive training program in preventing anterior cruciate ligament injuries in female athletes: 2-year follow-up. Am J Sports Med 2005; 33: 1003-1010.

12 Wong CX, Brooks AG, Lau DH, et al. Factors associated with the epidemic of hospitalizations due to atrial fibrillation. Am J Cardiol 2012; 110: 1496-1499.

13 National Centre for Classification in Health. The International Statistical Classification of Diseases and Related Health Problems, tenth revision, Australian modification (ICD-10-AM). Eighth edition. Wollongong: National Casemix \& Classification Centre, University of Wollongong, 2013.

14 National Casemix and Classification Centre. The Australian Classification of Health Interventions (ACHI) Eighth Edition. Wollongong: NCCC, Australian Health Services Research Institute, University of Wollongong, 2012

15 Australian Bureau of Statistics. Population. http://www. abs.gov.au/Population (viewed Apr 2017).

16 Royal Australasian College of Surgeons; Medibank Surgical variance report 2017: orthopaedic surgery. https://www.surgeons.org/media/25492528/surgical- variance-reports-2017-orthopaedic-surgery.pdf (viewed Nov 2017).

17 Beck NA, Lawrence JTR, Nordin JD, et al. ACL tears in school-aged children and adolescents over 20 years. Pediatrics 2017; 139: 1877.

18 Buller LT, Best MJ, Baraga MG, et al. Trends in anterior cruciate ligament reconstruction in the United States. Orthop J Sports Med 2014; 3: 2325967114563664.

19 Mall NA, Chalmers PN, Moric M, et al. Incidence and trends of anterior cruciate ligament reconstruction in the United States. Am J Sports Med 2014; 42: 2363-2370.

20 Hewett TE, Lindenfeld TN, Riccobene JV, et al. The effect of neuromuscular training on the incidence of knee injury in female athletes a prospective study. Am J Sports Med 1999; 27: 699-706.

21 Arendt E, Dick R. Knee injury patterns among men and women in collegiate basketball and soccer. NCAA data and review of literature. Am J Sports Med 1995; 23 : 694-701.

22 Aldous D, Chivers I, Orchard J. Seasonal and geographical analysis of ACL injury risk in Australia. Sport Health 2005; 23: 20.

23 Australian Bureau of Statistics. 4177.0. Participation in sport and physical recreation, Australia, 2013-14. Feb 2015. http://www.abs.gov.au/ausstats/abs@.nsf/ mf/4177.0 (viewed Apr 2017).

24 Murray CJ, Vos T, Lozano R, et al. Disability-adjusted life years (DALYS) for 291 diseases and injuries in 21 regions, 1990-2010: a systematic analysis for the Global Burden of Disease Study 2010. Lancet 2012; 380: 2197-2223.

25 Frank JS, Gambacorta PL. Anterior cruciate ligament injuries in the skeletally immature athlete: diagnosis and management. J Am Acad Orthop Surg 2013; 2: 78-87.

26 Werner BC, Yang S, Looney AM, et al. Trends in pediatric and adolescent anterior cruciate ligament injury and reconstruction. J Pediatr Orthop 2016; 36: 447-452.

27 Shea KG, Grimm NL, Ewing CK, et al. Youth sports anterior cruciate ligament and knee injury epidemiology: who is getting injured? In what sports? When? Clin Sports Med 2011; 30: 691-706.

28 Mather RC, Koenig L, Kocher MS, et al. Societal and economic impact of anterior cruciate ligament tears. J Bone Joint Surg Am 2013; 95: 1751-1759.

29 Ramski DE, Kanj WW, Franklin CC, et al. Anterior cruciate ligament tears in children and adolescents: a metaanalysis of nonoperative versus operative treatment. Am J Sports Med 2014; 42: 2769-2776.

30 Schneider S, Seither B, Tönges S, et al. Sports injuries: population based representative data on incidence, diagnosis, sequelae, and high risk groups. $\mathrm{Br} J$ Sports Med 2006; 40: 334-339.

31 Hunter DJ, Schofield D, Callander E. The individual and socioeconomic impact of osteoarthritis. Nat Rev Rheumatol 2014; 10 437-441.

32 Inacio MCS, Graves SE, Pratt NL, et al. Increase in total joint arthroplasty projected from 2014 to 2046 in Australia: a conservative local model with international implications. Clin Orthop 2017; 475: 2130-2137.

33 Schofield DJ, Shrestha RN, Percival R, et al. The personal and national costs of lost labour force participation due to arthritis: an economic study. BMC Public Health 2013; 13: 188.

34 Wright RW, Huston LJ, Spindler KP, et al. Descriptive epidemiology of the Multicenter ACL Revision Study (MARS) cohort. Am J Sports Med 2010; 38: 1979-1986.

35 Lind M, Menhert F, Pedersen AB. Incidence and outcome after revision anterior cruciate ligament reconstruction: results from the Danish registry for knee ligament reconstructions. Am J Sports Med 2012; 40: 1551-1557.

36 Lekkas C, Clarnette R, Graves SE, et al. Feasibility of establishing an Australian ACL registry: a pilot study by the Australian Orthopaedic Association National Joint Replacement Registry (AOANJRR). Knee Surg Sports Traumatol Arthrosc 2017; 25: 1510-1516.

37 Majewski M, Susanne H, Klaus S. Epidemiology of athletic knee injuries: a 10-year study. Knee 2006; 13: 184-188. 